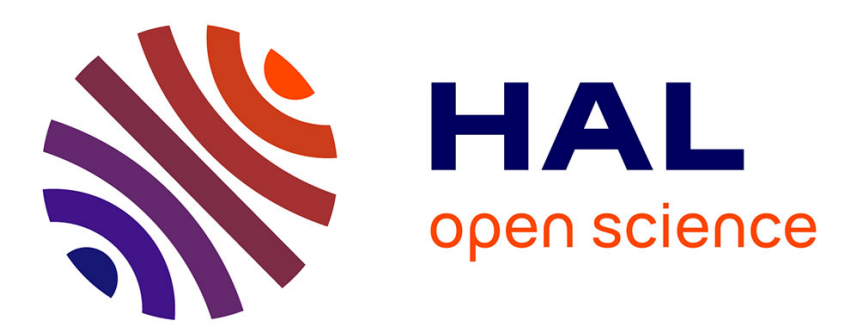

\title{
Rotational Moulding of Thermosets: Understanding of a Reactive Forming Process
}

Jérémy Viale, Fabien Nony, Philippe Mazabraud, Jean-François Gérard, Abbas Tcharkhtchi, Gwenaël Doulin

\section{- To cite this version:}

Jérémy Viale, Fabien Nony, Philippe Mazabraud, Jean-François Gérard, Abbas Tcharkhtchi, et al.. Rotational Moulding of Thermosets: Understanding of a Reactive Forming Process. International Journal of Material Forming, 2008, 1, p.803-806. 10.1007/s12289-008-0257-z . hal-00742241

\section{HAL Id: hal-00742241 \\ https://hal.science/hal-00742241}

Submitted on 16 Oct 2012

HAL is a multi-disciplinary open access archive for the deposit and dissemination of scientific research documents, whether they are published or not. The documents may come from teaching and research institutions in France or abroad, or from public or private research centers.
L'archive ouverte pluridisciplinaire HAL, est destinée au dépôt et à la diffusion de documents scientifiques de niveau recherche, publiés ou non, émanant des établissements d'enseignement et de recherche français ou étrangers, des laboratoires publics ou privés. 


\title{
Rotational Moulding of Thermosets: Understanding of a Reactive Forming Process
}

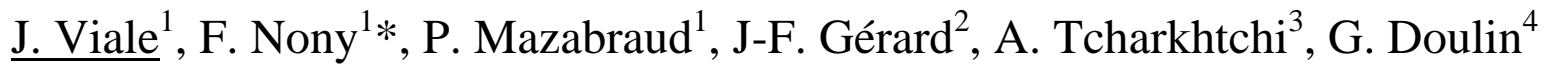 \\ ${ }^{1}$ CEA Le Ripault - BP 16, 37260 Monts, France \\ URL:www.cea.fr e-mail: jeremy.viale@cea.fr; fabien.nony@cea.fr*; philippe.mazabraud@cea.fr
}

${ }^{2}$ CNRS UMR 5223, INSA Lyon, LMM- bât Jules Verne, 20 av Albert Einstein, 69621 Villeurbanne, France

URL: www.insa-lyon.fr e-mail: jean-francois.gerard@insa-lyon.fr

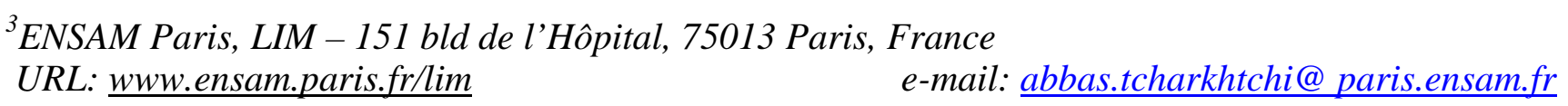

${ }^{4}$ RAIGI, - Arbouville, 28310 Rouvray St Denis, France

URL: www.raigi.com

e-mail:_doulin.gwenael@raigi.com

ABSTRACT: Physical and chemical transformations of polyurethane thermoset are studied by means of thermal analysis, infrared spectrophotometer and dynamic rheology. Gel point, which limits the material flow, is given as a function of conversion and as a function of time by kinetic law. Glass transition corresponding to a dramatic transformation of the material is also explored and connected to conversion and time. These ex situ characterizations are then exploited in terms of rotational moulding process parameters to improve the understanding and thus the control of the process. Therefore in situ thermal analyses are handled to confirm first results. Final parts thickness distribution is examined as a quantitative parameter of process quality. Finally, as a perspective, ultrasonic response is also studied as a new way to follow material evolution directly in the forming mould.

Key words: Rotational moulding, reactive process, chemorheology, polyurethane thermoset

\section{INTRODUCTION}

Rotational moulding is an industrially forming technique mostly applied to thermoplastics processing. Physical transformations such as fusion and solidification occur and lead to plastic hollow parts which size is counting between $2 \mathrm{~cm}^{3}$ and $50 \mathrm{~m}^{3}$. Previous works [1] on polymers reactive transformation by rotational moulding have been carried out in the early nineties but have not triggered industrial applications. This can be explained by the complexity of the transformation. In fact, reactive transformation requires not only control of physical phenomena but also of chemical transformation. The aim of this work is to increase the understanding of this transformation to finally optimize the control of the process and make easier the industrial applications of reactive rotational moulding. In the special case of polyurethane thermoset studied here, chemical bounds are established between isocyanate and alcohol functions. Hence the forming process is governed by the high reactivity of isocyanate group [2,3]. However, polyaddition of isocyanate on alcohol is the most likely reaction [4]. Literature enlights the auto catalyst effect of polyurethane function [5,6]. Reaction speed is also control by a tin complex catalyst concentration and kinetic law must integrate its effect. Sato's model [7] is appropriated to describe this kinetics.

$$
\begin{aligned}
\frac{d \chi}{d t} & =k_{1}\left([\mathrm{NCO}]_{0}-\chi\right)\left([\mathrm{OH}]_{0}-\chi\right)^{2} \\
& +k_{2} \chi\left([\mathrm{NCO}]_{0}-\chi\right)\left([\mathrm{OH}]_{0}-\chi\right) \\
& +k_{3}[\mathrm{cat} .]\left([\mathrm{NCO}]_{0}-\chi\right)\left([\mathrm{OH}]_{0}-\chi\right)
\end{aligned}
$$

where $\chi=$ conversion, $\mathrm{k}_{1}, \mathrm{k}_{2}, \mathrm{k}_{3}=$ reaction constants, $[\mathrm{NCO}]_{0},[\mathrm{OH}]_{0}$, [cat.]=initial concentrations in isocyanate, alcohol and catalyst

The chemical reaction has a direct effect on viscosity because it leads the molecular weight evolution. The establishment of three-dimensional irreversible network is homogeneous as the main reaction is a polyaddition [8]. This evolution is also split by two main transitions: the gelation which is connected to the percolation of the system and the vitrification which is linked to the decrease of chains mobility. The phenomenon of gelation is related to the apparition of a master chain connecting the 
whole system. This appears at a constant conversion depending on the formulation studied [9]:

$\chi_{g}=\sqrt{\frac{1}{r} \frac{1}{\left(\overline{F_{w}}-1\right)\left(\overline{G_{w}}-1\right)}}$

where $\chi_{\mathrm{g}}=$ conversion at gel, $\mathrm{r}=[\mathrm{NCO}] /[\mathrm{OH}], \mathrm{F}_{\mathrm{w}}$, $\mathrm{G}_{\mathrm{w}}=$ average functionality of isocyanate and polyol.

The second major transition which can occur during material transformation is the vitrification. This transition corresponds to the transformation of the system from a liquid or a gel into a glassy state [8]. Below glass transition temperature (Tg), the chemical reaction is considered to be stopped. All this chemorheological evolutions can be displayed on a single diagram representing a "map" of physical properties: Time Temperature Transformation (TTT) diagram [10]. Thank to this diagram, process is optimized in term of understanding and control. In the present paper, the polyurethane is characterized in order to know exactly its evolution during the reactive forming process. Then the process is depicted in term of comparison with the former classical rotational moulding. Finally perspectives are proposed to connect experimentally ex situ characterization to in situ results.

\section{EXPERIMENTAL CONDITIONS}

Kinetics is studied by infrared spectroscopy. An isocyanate/polyol liquid melt is introduced in a temperature regulated sample holder from Harrick Scientific and the conversion is followed by a spectrophotometer during two hours.

The $\mathrm{Tg}=\mathrm{f}(\mathrm{t})$ curve are obtained by thermal analysis realised on a Q200 from TA Instruments. Material cured at different rates is first quenched at $-70^{\circ} \mathrm{C}$ then it is heated at $10^{\circ} \mathrm{C} / \mathrm{min}$ until $210^{\circ} \mathrm{C}$. These curves directly give $\mathrm{Tg}$ and conversion.

Gel time is determined by dynamical rheology. Liquid polymer is laid down in ARES plate-plate geometry. A multiwave signal is imposed to the material. Then, $\tan \delta$ is followed at different frequencies as a function of time. Gel time corresponds to the time until $\tan \delta$ obtained at different frequencies cross [11]. Tests are handled at different temperatures. Finally, gel time can be plotted for different temperatures.

\section{MATERIAL CHARACTERIZATION}

As a beginning, thermosets behaviour determination appears essential. The complete study includes chemical reactivity, viscoelastic evolution and finally Time-Temperature-Transformation (TTT) diagram as a synthesis of ex situ results.

\subsection{Chemical reactivity}

Kinetics is studied following the consumption of isocyanate function. Conversion is plotted as a function of time.

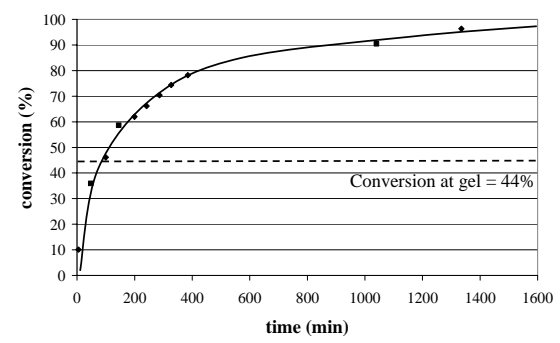

Fig. 1. Conversion determined by FTIR (isocyanate consumption as a function of time)

Gelation is independent of catalyze rate, hence it is possible to determine gelation as a function of time thank to conversion at gel for non catalyzed system. A 44\% conversion at gel is obtained theoretically by Macosko-Miller equation applied to the system. In that case gelation occurs $90 \mathrm{~min}$ after the beginning of the reaction. It implies that the major part of chemical evolution occurs at the beginning of the process.

\subsection{Chemorheology of thermoset polyurethane}

As a second part of the ex situ characterisation of such a reactive material, rheological behaviour have to be determined.

\section{2.a Gelation}

At the gel time, liquid material stops flowing. Lots of gelation definitions have been developed. Chambon-Winter definition is selected for this study because of its frequency independence [11]. Tests are handled at different temperatures.

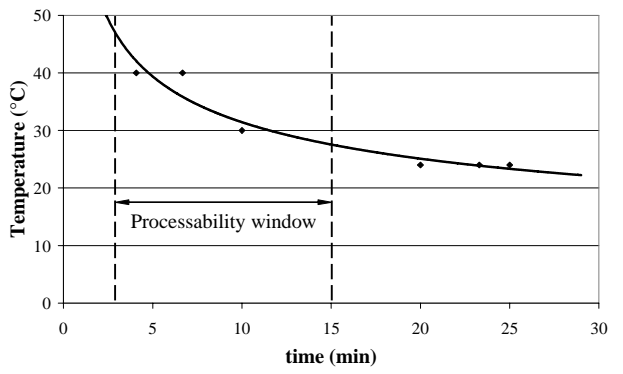

Fig. 2. Gel time at different temperatures 
A forming process window appears. It is limited for low time by the material repartition; gel time must be higher than $3 \mathrm{~min}$. The other limit is a chosen parameter: process must take less than $15 \mathrm{~min}$ to be competitive.

\section{2.b Vitrification}

In the process, vitrification is connected to the apparition of a sufficient rigidity to unmould the part.

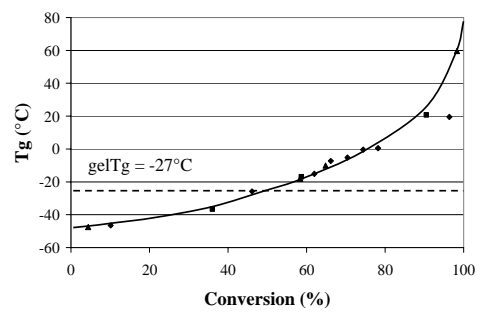

Fig. 3. Tg versus conversion for different curing temperatures

A gelTg is observed at $-27^{\circ} \mathrm{C}$. First of all, this shows that the conversion until gel is not disturbed by vitrification at ambient temperature transformation. It appears also that the last percents in conversion control high modification of material Tg. Therefore, an adapted post-cure is important.

In order to build the TTT diagram, it is needed to plot the time that it takes to vitrify the reactive system at different temperatures. Previous curve is combined with kinetics curve such as Fig. 1 obtained at different temperatures.

\subsection{Results compilation and TTT diagram}

Ex situ results are finally combined in an isothermal TTT-diagram [10]. This "mapping” of material properties is an appropriate instrument to increase the understanding and to optimize the process.

\section{REACTIVE FORMING PROCESS}

Material behaviour is characterized during evolutions equivalent to process conditions. Thank to TTT diagram, it is possible to determine the time to solidify a part and finally to predict the cycle time.

\subsection{Effects on classical parameters}

As in classical rotational moulding, there are very few controlling parameters during the process. The temperature can be controlled using in situ thermal sensors (Datapaq ${ }^{\circledR}$ ) and oven or infrared lights by heat generator. Rotation speeds on the two perpendicular axes can also be modified. Finally it is possible to control the time it takes to heat or cool the part. The main difference with classical rotational moulding is the fact that reactive transformation can also be controlled by chemical parameters: catalyst concentration, mix quality, conversion of prepolymers. At an appropriate catalyst concentration, thermal evolution is control by kinetics only. In this case, cycle time can be decreased below 15min. In situ thermal analyses show the evolution of temperature at different locations of the rotational moulding system:

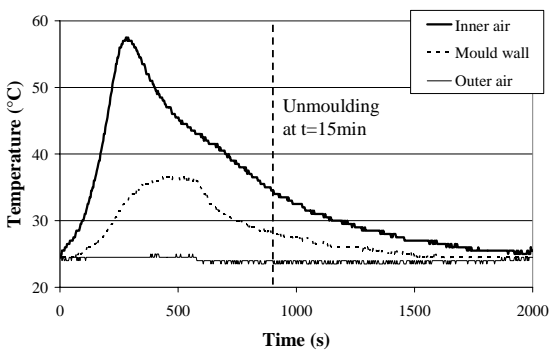

Fig. 4. In situ following of temperature as a function of time

\subsection{Final parts characterization}

Parts realised are oblong tanks. Previous works [12] impose, for this geometry, a speed ratio of 7/2.

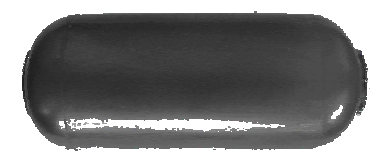

Fig. 5. Rotational moulded part

Final parts are cut at the base of each hemispheres and the thickness distribution is measured on 40 points taken on the cylindrical section. Thickness distribution is chosen as a quantitative criterion of part quality.

A comparative summary is established between classical rotational moulding using fusion/ solidification processes and reactive rotational moulding using also chemical transformations.

\begin{tabular}{|c|c|c|}
\hline $\begin{array}{c}\text { Rotational moulding } \\
\text { technique }\end{array}$ & Classical & Reactive \\
\hline Cycle time & $\mathrm{t}>1 \mathrm{~h}$ & $\mathrm{t}=15 \mathrm{~min}$ \\
\hline Temperature order & $\mathrm{T}>120^{\circ} \mathrm{C}$ & $\mathrm{T}=25^{\circ} \mathrm{C}$ \\
\hline Speed ratio (V1/V2) & $7 / 2$ & $7 / 2$ \\
\hline $\begin{array}{c}\text { Thickness } \\
\text { distribution }\end{array}$ & $\mathrm{d}<5 \%$ & $\mathrm{~d}=8 \%$ \\
\hline
\end{tabular}

Fig. 6. Comparative table classical versus reactive processing

\subsection{Instrumentation as perspective}


During a polymer forming process, viscoelasticity is the key parameter. Viscosity part control the spreading of the material in the right shape and elastic part is connected to final part mechanical stability. Presently, only thermal sensors are available for rotational moulding. For thermoplastics processing, this is sufficient because for a given polymer, viscosity is a simple function of temperature (shear rate can be neglected in rotational moulding). But in reactive process, it is not the case. Reactive rotational moulding requires a new type of sensors giving a value directly connected to viscosity. In the literature, ultrasonic response has been applied to polymer transformation studies such as glass transition [13]. This in situ analyses technique is evaluated for the polyurethane thermoset studied here. Liquid isocyanate/polyol melt is laid down a steel plate at an average thickness of $3 \mathrm{~mm}$. A $3.5 \mathrm{MHz}$ ultrasonic sensor is attached below the plate and the signal is emitted through the steel plate and the polymer. The amplitude of the first echo from the interface steel/polymer is plotted as a function of time.

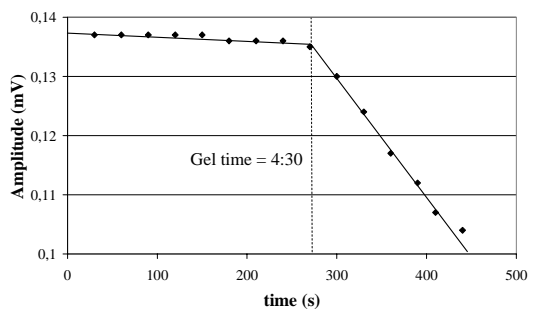

Fig. 7. Ultrasonic response versus time

First of all, it is important to note that the amplitude of the echo is a strictly decreasing function of time. A relation can be established between this echo and the evolution of the material. Then a slope change is observed. The theory of ultrasonic analysis announces that the more rigid a material is the better the signal is transmitted. The increase of chemical conversion is connected to the increase of molecular weight and so finally to the increase of part rigidity. Hence the amplitude of reflected signal from steel/polymer interface decreases with conversion increasing. This prospective evaluation is promising and will be applied to rotational moulding equipment for further investigation.

\section{CONCLUSION}

Properties mapping are obtained as a function of time and temperature. This isothermal mapping is then exploited to the process setup but there is some restriction. In fact, the reactive transformation is not isothermal. The application of Continuous Heating Transformation (CHT) diagram should fit better the real process. The exploitation of ultrasonic analysis comes to complete the simple thermal in situ measure. The combined instrumentation will give a precise representation of the viscoelastic evolution of the material during the reactive rotational moulding process.

\section{ACKNOWLEDGEMENTS}

Authors thank Pr M. Lethiecq and J. Fortineau from LUSSI laboratory at the ENIVL, Blois (France) for fruitful discussions and experimentation dealing with ultrasonic analysis applied to curing polymers.

\section{REFERENCES}

1. B.E. Harkin-Jones, Rotational Moulding of Reactive Plastics. Thesis from The Queen's University of Belfast, Belfast (1992).

2. J. Viale, F. Nony, P. Mazabraud, J-F. Gérard, A. Tcharktchi, G. Doulin, Rotomoulage de polyuréthanes thermodurcissables. Oral communication at RTS 2007 and paper to be published: Matériaux techniques (2008)

3. C. Hepburn, Polyurethane elastomers, $2^{\text {nd }}$ Ed., Elsevier Applied Science - London (1991).

4. F. Dimier, Injection de systèmes réactifs : détermination de lois cinétiques et rhéologiques et modélisation. Thesis from l'Ecole Nationale Supérieure des Mines de Paris., Paris (2003)

5. L. Thiele, Reactions of isocyanates and the catalysis in polyurethanes. Polym. Eng. Sci. 37 (1979) 1238-1246.

6. J.E. Kresta, K.H. Hsich, The cocatalytic effect of carbamate groups in cyclotrimerisation of isocyanates. Makrom. Chem. 179 (1978) 2279-2282

7. M. Sato, The rates of reaction of 1-alkenyl isocyanates with methanol. J. Am. Chem. Soc. 82 (1960) 3893-3897

8. J-P. Pascault, H. Sautereau, J. Verdu and R.J.J. Williams, Thermosetting polymers, Marcel Dekker, Inc., New York - Basel (2002)

9. D.R. Miller, C.W. Macosko, New derivation of post gel properties of network polymers. Macromol. 9 (1976) 206211

10. J.K. Gillham, The Time-Temperature-Transformation (TTT) State Diagram and its Role in Determining Structure/Property Relationships in Thermosetting Systems, Polym. Sci. and Tech. 22 (1983) 215-225

11. H.H. Winter, F. Chambon, Analysis of linear viscoelasticity of a crosslinking polymer at the gel point. J. of Rheo. 30 (1986) 367-382

12. R. J. Crawford, M.P. Kearns, Practical guide to rotational molding, UK: RAPRA Technology Ltd - Shawbury (2003)

13. N.T. Nguyen, M. Lethiecq, J-F. Gérard, Glass transition characterization of homogeneous and heterogeneous polymers by an ultrasonic method, Ultrasonics 33 (1995) 323-329 